\title{
ROLE OF ISLAMIC AZAD UNIVERSITY IN GROWTH AND EXPANSION OF EDUCATION AND RAISING LEVEL OF GRADUATION (CASE STUDY: ISLAMIC AZAD UNIVERSITY, SARI BRANCH)
}

\author{
Abdollah Ebrahimi \\ Ph.D.Candidate.Department of Architecture, Faculty of Art and Architecture, Science and Research \\ Branch, Islamic Azad University,Tehran,Iran \\ Eb1526300@gmail.com \\ Farah Habib \\ Professor of Architecture, Faculty of Art and Architecture, Science and Research Branch, Islamic Azad \\ University, Tehran, Iran \\ F.habib@srbiau.ac.ir \\ Iraj Etessam \\ Professor of Architecture, Faculty of Art and Architecture.Science and Research Branch, Islamic Azad \\ University, Tehran, Iran \\ I.etessam@srbiau.ac.ir
}

\begin{abstract}
Islamic Azad University as an educational institution was founded more than a quarter century ago. It has a wide role in growth and expansion and development of education and raising the level of graduation and excellence of community's people in Iran. This is because education of human labor for entering the market is the activity of universities, including Azad University. This activity has a great effect on growth and development of the country. It itself was also affected by this growth and development. This growth is physically more tangible in university. It has become common in the minds of the public as an undeniable truth. Islamic Azad University made its surrounding environment in line with itself in its growth and development path. Not only it had an effect on its body and surroundings but could also change city's development path in most small and medium developing cities while imposing it on other land uses. It itself became the factor of determining the way of new textures' formation and old textures' evolution. The research methodology is functional in terms of purpose. The study method is descriptive and analytical in terms of method and nature. Information collection method had been library, documentary, and field studies (questionnaire). The research statistical population includes 370 residents of surrounding neighborhoods. However, 400 questionnaires were distributed and 385 questionnaires were completed and answered to ensure. SPSS analytical software and Excel has been used to analyze information. The results of this research indicate the effectiveness of university in economic, physical, social and cultural dimensions.
\end{abstract}

Keywords: University, spatial structure, social, economic and physical effects and surrounding neighborhoods

\section{INTRODUCTION}

\section{Problem statement}

At the present era the university has become a phenomenon that can be analyzed from different aspects. The thing that today has become a reality in the international arena is physical role and effectiveness of university in social, economic, cultural, scientific and political dimensions. Its importance is increasing day by day. 
Universities have been intertwined in the fabric of scientific and research relations and mechanisms of social and economic development that it is not possible to separate their role from complexities of development of the path. Also, the production process of material capital that is not something other than economic wealth has been tied closely with scientific activities and training of specialized forces in universities.

Thus, we chose Islamic Azad University, Sari Branch for several reasons. Firstly, primary studies and observations show that this university with a history of nearly a quarter century has caused many changes in the spatial structures of its surrounding. Undoubtedly, it will change this region to one of the urban very active cores in Sari in the near future with operation of the plans and projects, including hospital. The next reason is tangibility of many created changes after foundation of this university in spatial structures of the surrounding neighborhoods.

\section{Research goals}

1. Investigate the physical changes affected by the existence of academic branch on Sari City and investigate the changes' trend

2. Social, cultural, and identity of the body and surrounding texture affected by the existence of academic branch on the city and suburb of Sari City

\section{Institutionalize academic and scientific role for this area of Sari City}

4. Improve the effects of Islamic Azad University, Sari Branch on spatial structures of surrounding texture

\section{research questions}

1. Has the establishment of Islamic Azad University, Sari Branch had an effect on physical structure and attraction of different land uses?

2. How had been the economic effects of Islamic Azad University, Sari Branch in surrounding neighborhoods?

3. Had establishment of university had an effect on demographic and social structure of its surrounding neighborhoods?

4. To what extent Islamic Azad University, Sari Branch had been effective in changing the path of urban growth and development?

5. What are the effects of academic branch on physical changes of texture, lands use, density of the surrounding residential, departmental, commercial, and so on units and change of physical development trend, and giving orientation to it?

6. Has mutual need led to disorder in spatial body of the branch margin?

\section{Research methodology}

The used method in this research is descriptive, analytical that in the first is introduced the studied concepts, and it is conducted with the use of polling centers data and also equipped libraries and then field studies by questionnaire and interview from inhabitants about the performed changes and how it effects on the lives of inhabitants and desirability degree of that, in the following the current situation of intended region is described, that it is to the analysis and evaluation and presentation of solutions. After collecting data "Excel and SPSS" software was used for the analysis of the data. It should be noted that from t-student test and Friedman test we will use for analyze the data. Friedman test is a non-parametric test (intergroup) that, that is used for comparing average of the ranks among of k-variables (Group). 


\section{THEORETICAL FOUNDATIONS}

\section{The concept of university}

Choosing word of the university equal to word of the university and facility equal to word of the facility and professor equal to word of the lecture and students equal to word of the student and other words has been a special meaning in our community. and the university word has been selected because of that is useful from concept of "knowledge" with in term of time and in term of time place "Gah" , it is too, places of the forming knowledge, that's growth center than and place of science's prosperity. Also, a boiling or seeker movement is hidden in the word of university or students and it means that knowledge has rooted inside individuals and it is followed with the continuous search and research. Aside from the terminology of universities also they are phenomena in the scientific concept that have been formed that completing epistemology of human , Basically, the phenomenon of university has been formed that shows the human cognition in a short time with the trainings that are inside of that . (Khaleghi moghadam: 1990)

\section{Aims of creating university}

Our expectation of the university is not the same of past in the twenty-first century. Universities should be having a dominant role in the economic, cultural, and social life. In the present century mission of the university is knowledge creation, In addition to it prepares the youth for enter to the employment market. And also is expected from university graduates that they to be have the active participation in the social, political affairs. It is expected from universities that to be have an important role even in the local economy.

\section{Theory of action}

Action theory has roots in the "karma kas vebr" in the field of social action. So, Weber had based his work on the hypotheses in the field of activists and action. But his main interest was attentive of the effect of cultural and structural requirements on the activists. Action theory acts in the thought and individual action instead of emphasizing on this aspect of Weber's work. In abstract of "Roscoe Hynkel" principles of action theory is as follows (George Rytrz: 2005)

1. Humans social activities originate from awareness to themselves, others and external positions.

2. Humans act for achieve to their mental intentions, destinations and aims.

3. Humans use from tool, act techniques and methods and instrument proportional with their aims.

4. Their field of act is limited because of conditions and requirements that cannot be closed.

5. Humans measure, evaluate and select what that they have performed or are performing that or will be performed, by the enforcement of volition or the judgment.

\section{Conflict theory}

The word of Conflict has been taken from the root of Configure means collisions and fight. It is called conflict whenever two or more persons or groups to be in apparent conflict and disagreement mixed with violence in term of violation in the thought and the benefits. for this phrase has been considered equivalents such as conflict, contrast, battle, aberration, duality and animosity and successive thaer used in the Marxist sociology and it is from major ideologies in the sociology.

\section{Systems theory}

During social thoughts, can be evaluated and identified the two intellectual major flows in the various social affairs and phenomena : First, intellectual flow believed to the lawlessness of affairs and phenomena that it comes from messy and chaotic thoughts and it had been propagator a kind of intellectual chaos and confusion, spiritual passivity and nihilism. Meanwhile, systematic attitude, knows related to each other and effective all existing phenomena in the nature and society and it considers systematic their stable relationships that forms existing process of the phenomena, limitation of each phenomenon is determined in relation to other phenomena, This means that a phenomenon is also an 
element of a larger system as system of its elements. Each phenomenon or object, while is considered the system than to its elements. It is considered a subsystem compared to larger systems. (Golabi 1990)

\section{Existentialism theory}

existentialisms theory is a philosophical approach, it emphasizes on the independence, free volition in the individual responsibility of humans consumedly, they believe, science and scientific determinism-like collision, that it assumes the human lack of the wisdom and the volition cannot be able help to the recognize of original existence human. Because the most important issues that are related to the human identity, are beyond from access of science. So existentialisms opinion, the mission of higher education or the highest quality level from the university is something except creating appropriate fields for individual growth and prosperity of more individual ability (Hosseini and Latifian 2008)

\section{Growth pole theory}

Growth pole theory emphasizes on the enormous investment in the industry, in the largest cities. In this theory, the governments can provide the motivations of economic growth. this economic growth spreads in the outside urban centers and it leads to the zonal social-economic development .thus in the growth pole theory is giving priority to the cities that social-economic development of cities leads to the socialeconomic development of the villages. This theory emphasizes on the performance of free market forces that, that's side effects, is motivation of social-economic development across the region. In a growth pole theory, investment in the industry is considered as engine of development for agricultural and commercial activities, and capital and labor move in that.

\section{Influence dimensions of the universities on the communities development}

University is an institution that it is in the top of the pyramid of scientific institutions. On the one hand correct performance of universities, it brings development and progress and on the other hand it improves the development process of community to the higher place as a positive feedback. On the one hand the universities are considered as subsets of the higher education system in the development process of a country that they play a key and vital role as a centers that breed and prepare the efficient, worthy and with skills manpower, for answering to real needs of community in different fields because the universities try for development with their outcomes to the community actually.

In summary, it can be said that higher education system plays a vital role in the development process and creating balance between various dimensions of development of country. The principled investment in this section is considered the creating facilities and convenience for future generations and the correct action for scientific development of country (Fereidoon 2004).

\section{Dimensions of effectiveness of universities on development of communities}

University is an institution that is at the top of the pyramid of scientific institutions of a community. Proper performance of university on the one hand, brings development and progress, and on the other hand transfers the development trend of community as a positive feedback to loftier place.

Universities on the one hand are posed as the subsets of higher education system in development process of a country. They take a key and vital role as centers that train and prepare efficient, competent and skilled human force to response the real needs of community in different fields. This is because universities practically take step in the way of development with their outputs to the community.

Briefly, it can be said higher education system has a fundamental role in the development process and balancing between various dimensions of development of the country. Methodical investment in this section is actually considered creation of facilities and conveniences for future generations and the proper measure

\section{Relationship between city and university campus}


Bolton had been revived in the late twentieth century based on a combination of physical, cultural and economic forces that had been penetrated in the city life through universities and colleges. There was a special relationship between the city and its universities. This indicates the existence of a special relationship between urbanism and architecture of the city and its universities. Are there any elements and factors in this physical relationship that can create positive quality effects for the city and the universities in the future?

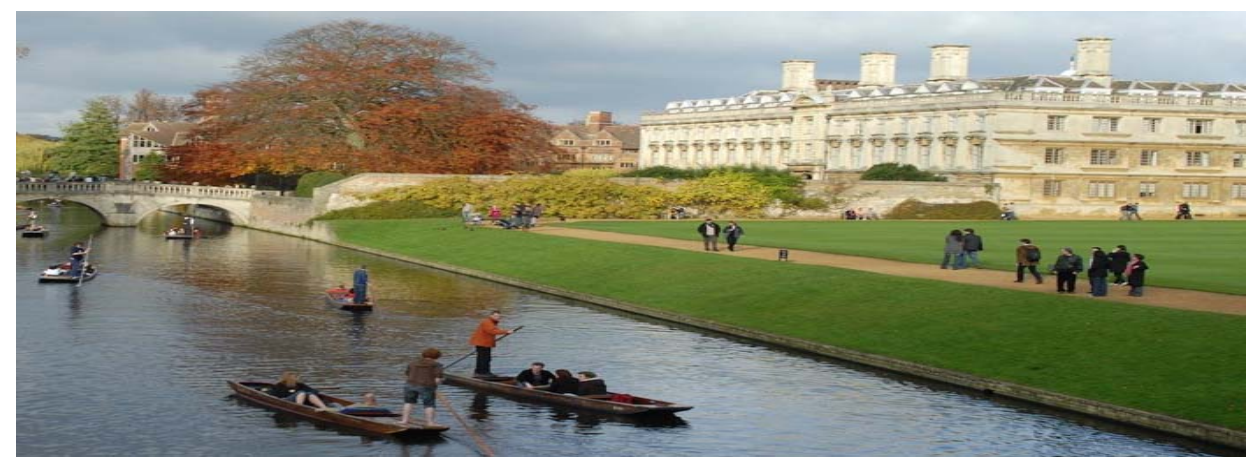

Image 1: Cambridge University that people are using the campus space

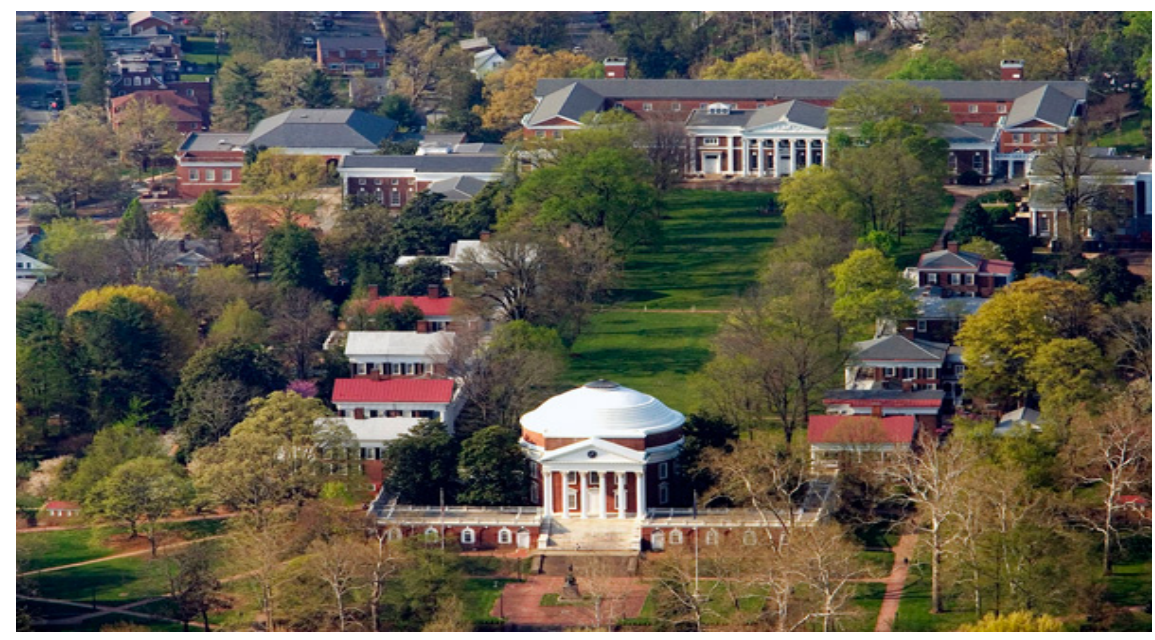

Image 2: University of Virginia

\section{RESEARCH FINDINGS}

\section{Testing hypotheses}

Data is reviewed and analyzed with regard to the validity and reliability of questionnaire items. Onesample $t$ test was used to test the research hypotheses and the questionnaire items were classified in the environmental, economic, social and cultural group and the data obtained were analyzed. Friedman test was used for ranking among the components of sustainable development and to determine the maximum and minimum affected areas of Azad University of Sari. 
Since the normality of the data is not important in performing one-sample $t$ test, but approximate normality of the data, is appropriate to perform this test. However, Skewness and kurtosis of the data was examined to assess the normality of the data. Skewness is a measure of symmetry or asymmetry of the distribution function. For a perfectly symmetrical distribution is the zero Skewness and for an asymmetric distribution with kurtosis towards higher values is positive Skewness and for asymmetric distribution with kurtosis towards smaller values is negative Skewness. Kurtosis represents the height of a distribution. In other words, kurtosis is a measure of the height of the curve at the point of maximum. Maximum is value of kurtosis and Skewness for normal distribution is between -3 to +3 .

Table 1:Study of the normality of the studied variables

\begin{tabular}{|c|c|c|c|c|}
\hline Variable & Mean & Sd & Skewness & Kurtosis \\
\hline $\begin{array}{c}\text { Social and cultural } \\
\text { development effects }\end{array}$ & 3.92 & 0.652 & -0.943 & 2.233 \\
\hline physical development effects & 3.91 & 0.671 & -0.868 & 2.066 \\
\hline Economic development effects & 3.94 & 0.692 & -0.755 & 0.881 \\
\hline
\end{tabular}

First major hypothesis: the establishment of Islamic Azad University of Sari has a positive impact on social and cultural development areas surrounding the University.

test results of the first main hypothesis indicate that a t-single sample test value is (42.74) the Table 4-16 shows that There is a significant difference with confidence of $99 \%$ and error level smaller than $0.01(\mathrm{p}$ $<0.001$ ). The mean of statical population (3.92) is higher than given average (2.5). Thus it can be said that the null hypothesis of research based on lake of relationship between the study variables is rejected and the research hypothesis is confirmed.

Table 2: $t$ test results for the main hypothesis of research

\begin{tabular}{|c|c|c|c|c|c|c|}
\hline Variable & $\mathbf{t}$ & $\begin{array}{c}\text { Degrees } \\
\text { of } \\
\text { freedom } \\
\text { (df) }\end{array}$ & $\begin{array}{c}\text { Significant } \\
\text { level }\end{array}$ & $\begin{array}{c}\text { Mean } \\
\text { difference }\end{array}$ & \multicolumn{2}{|c|}{$\begin{array}{c}\text { confidence interval \%95 } \\
\text { of the difference }\end{array}$} \\
\hline $\begin{array}{c}\text { Social and cultural } \\
\text { development effects }\end{array}$ & 42.74 & 384 & 0.000 & 1.42 & 1.35 & 1.49 \\
\hline $\begin{array}{c}\text { physical development } \\
\text { effects }\end{array}$ & 41.35 & 384 & 0.000 & 1.41 & 1.35 & 1.48 \\
\hline $\begin{array}{c}\text { Economic } \\
\text { development effects }\end{array}$ & 40.69 & 384 & 0.000 & 1.41 & 1.37 & 1.50 \\
\hline
\end{tabular}

Second major hypothesis: the establishment of Islamic Azad University of Sari has a positive impact on the physical development of surrounding the University areas.

test results of the first main hypothesis indicate that a t-single sample test value is (41.35) the Table 4-16 shows that There is a significant difference with confidence of $99 \%$ and error level smaller than $0.01(\mathrm{p}$ 
$<0.001$ ). The mean of statical population (3.91) is higher than given average (2.5). Thus it can be said that the null hypothesis of research based on lack of relationship between the study variables is rejected and the research hypothesis is confirmed.

Third major hypothesis: the establishment of Islamic Azad University of Sari has a positive impact on the economic development of surrounding the University areas.

test results of the first main hypothesis indicate that a t-single sample test value is (40.69) the Table 4-16 shows that There is a significant difference with confidence of $99 \%$ and error level smaller than $0.01 \mathrm{p}$ $<0.001$ ). The mean of statical population (3.94) is higher than given average (2.5). Thus it can be said that the null hypothesis of research based on lack of relationship between the study variables is rejected and the research hypothesis is confirmed.

According to Table 2, it is observed that the t-value of all three factors is higher than standard value. So can be concluded the Islamic Azad University on the surrounding areas has social-cultural, physical and economic effects, and all three factors are effective in sustainable development.

\section{CONCLUSION}

Has establishment of Islamic Azad University, Sari Branch had an effect on spatial and physical structure and attraction of different surrounding land uses?

As has been mentioned in the previous chapters Islamic Azad University, Sari Branch has been able to act effectively on the development of physical structure of surrounding neighborhoods. Increase of the surrounding population and consequently the need for more residential units, and on the other hand interest of employees to settle in the vicinity of the university has enhanced constructional density in surrounding environments. We can see its sample in creating residential suburbs and changing pattern of construction of villa to apartment and construction of apartment complexes in the vicinity. On the other hand, increase of residential units and subsequently increase of population needs and demands other land uses to fulfill the daily needs of residents. We see the creation of new land uses, including department stores (Iranian and Negin, and so on) in this regard in responding to the needs.

\section{How had been the economic effects of Islamic Azad University, Sari Branch in surrounding neighborhoods?}

It can be said about the economic effects of Islamic Azad University on surrounding neighborhoods that establishment of the University has acted on its development as an increasing value on the development of surrounding neighborhoods. We saw based on the cases that were stated in the third chapter that although increase of land cost and building rent, inflation and specific economic conditions of different years had been temporal, but a mutation has been created in estate and buildings' rent simultaneous with establishment of the university.

All of them had been resulted from desirability and more demand for purchasing lands existing in the surrounding neighborhoods of the university. Of course, as was described in the field studies, the university has increased the level of residents' welfare, created new jobs, and increased the amount of consumption of goods and services in its surrounding neighborhoods. It should be noted that it has been sufficed in this regard due to lack of access to information and data of questionnaire.

Had establishment of university had an effect on demographic and social structure of its surrounding neighborhoods?

Considering that Islamic Azad University, Sari Branch not only has an effect on the surrounding environments but also has been with an effect on the whole path of the sea road (Farahabad Boulevard) 
and it has brought persuasion of transfer of other academic branches from other parts of Sari city to this path (seventeen public and non-profit academic branches).

Given that the vast majority of their personnel and professors are non-native and on the other hand tourism being of this academic axis and high attraction in the desire to live in this axis has caused a significant number of professors to be settled in the surrounding environments of academic branches as professor's suburbs. On the other hand the presence of a large group of students and the need for rental houses has changed the region population significantly.

Levels of the region literacy has have increased according to literate being of the new residents. The desire for education and higher educations has been created in traditional group of the region. Subsequently we see change in the reference groups in these regions. This is because the region population has had more desire to work in agricultural affairs and the related jobs.

But the desire to new jobs has been appeared there after the incidence of new population according to the new needs, including student services (printing and copying, food and grocery store and so on) and services between the road (cars services and traveler families and so on) by the younger generation.

To what extent Islamic Azad University, Sari Branch had been effective in changing the path of urban growth and development?

As has been mentioned in the previous chapters, communicational networks have been developed after the establishment of Islamic Azad University Branch in Sari Branch to the sea and its large student population. It particularly has led to creation of bus lines from Valiasr Square to Islamic Azad University Sari Branch and surrounding villages, and equipment of the sea boulevard with lighting and several pedestrian bridges and under study being of monorail line from Sari to the sea (According to a study between the Sari Branch and Sari governorship and road). These all have caused this axis to have a very high boom.

Creation of infrastructure has led to migration of seventeen academic branches from other parts of the city to this axis. Consequently, the creation of small and large suburbs and different land uses in the vicinity of each of the branches has automatically provided the causes of path change of Sari city development from East and West to the North. Several times increase of the lands' price in this axis proves this claim.

What are the effects of academic branch on physical changes of texture, lands use, density of the surrounding residential, departmental, commercial, and so on units and change of physical development trend, and giving orientation to it?

As it has been mentioned in the above paragraphs, Islamic Azad University, Sari Branch can be mentioned as the main factor that has caused increase of residential density and increase of the number of constructional floors, as well as creation of apartment residential complexes around the university. This is because the surrounding environments and even Farahabad axis were utilizing limited land uses and limited constructional density and low altitude according to Google Maps in 2003 before the presence of this branch.

A lot of residential and apartment complexes and service complexes have been created by the establishment of Sari Branch to fulfill the needs of great student population that includes 12,000 students of Islamic Azad University, Sari Branch and tens of thousands of students from other academic branches settled in this axis.

A significant proportion of the professors and employees transferred to this axis should also be added to this population that needs services. Subsequently the path change of the city development and the programs under study accelerate urban planners of this development. 


\section{Has mutual need led to disorder in spatial body of the branch margin?}

Disorders had been naturally predictable considering that the establishment of the branch in the urban structure from before and even the future development had not been predicted, and on the other hand the surrounding texture capacity also had not been at the extent of mass of the new population. Urgent need of the new population had led to construction of new suburbs and apartments regardless of urban regulations.

\section{SUGGESTIONS}

A) Amendment at the scope of city and county in such a way that Sari axis to the sea to be exited to a radius of scope of governorship and bailiwick and to be added to the urban domain to have a detailed and comprehensive plan in terms of urbanism. The over-constructions to be prevented and a coordination to be created between the departments related to urban services in order to create the necessary harmony in the body and content in buildings and facades and even the facilities related to urban transportation.

B) Conducting studies on location and construction of the land uses required for the university such as cultural centers and parking and so on

C) Transfer of those surrounding land uses that are incompatible with the educational and cultural and even biological environment (such as poultry farms, etc.) and other obtrusive jobs from vicinity of the university out of bounds or to industrial suburbs.

D) Implementation of high-speed transportation links and suggestion of the author or the university preferably Monorail (implementation of urban train seems very difficult because of many cuts over the path of Sari to the sea for access to 60 villages branching from this axis) to reduce traffic and road accidents

E) Creation of cultural spaces with distinct and excellent features in the adjacent neighborhoods to help to the cultural richness of the region to stand against some of the cultural invasions resulting from change of demographic texture

F) Creation of public spaces in the vicinity and surrounding neighborhoods as the civic beating heart of cultural and artistic and educational centers in this region

\section{REFERENCES}

Oppenheim, Norbert - 2008 - models used in the analysis of urban and regional issues - Translation: Tabibian, doctor Manuchehr- Tehran University Press

Esfandiar skilled Iraj Asadi, Autumn 2010, the city typology of urban and regional areas, beautiful publication - Architecture and Urbanism (43)

Almasi, Ali Mohammad, 1991, the history of education, Islam and Iran, knowledge today,

2. Ostrovsky, Vatslaf - 1999 - Urban contemporary translation: E'tezadi, Laden - Nashr

Bagheri, Noparast, Khosro, 2010, Introduction to the Philosophy of Education of the Islamic Republic of Iran, two volumes. Cultural and Scientific Publications,

Bamdad, Bandaralmluk, 1968 Constitutional Revolution and White Revolution Iranian women. Tehran: Ibn Sina, Page 99

Bahrain, SH - 1996 - Analysis of urban space in relation to the economic patterns of consumers and conditions for design - Institute of Tehran University Press

Bahrain, Seyyed Hassan -1998 - urban design process - Institute of Tehran University Press

58. Bijan, A., 1971, the course of civilization and education in ancient Persia, Avicenna

Papal Yazdi, Mohammad Hossein - Rajabi Sanajrdy, H. - 1389 - Theories of the city and surrounding ICTS study of humanities universities (side) 
Potter, Rabrt.b. - Evans, tuberculosis Lloyd -2005 - a city in the developing world - translation: Irandoust, K., farmer Manshadi, Mhdy- Ahmadi, M - Publishing municipality and Dhyary country

Pour-Mohammadi, Mohammad Reza - 2010 - land use planning - organization of study and universities Humanities Textbooks (side)

Pirnia, H., 2001, Iran ancient history, charm, Volume III

Hafeznia, MR (2008), Introduction to Research Methods in Human Sciences, Tehran: Organization of Study and Compilation of Humanities Books (side).

B) External resources

Anamaria de Aragão Costa Martins and Melchior Sawaya Neto, 2007, The Impact of University Campuses on Disperse Urban Contexts: Case Study of Brasillia, Brazil, Lincoln Institute of Land Policy

Animesh K. Jain, 1997, BASIC THEORY OF MAGNETS, Brookhaven National Laboratory, Upton, New York 11973-5000

Antonio P. Russo, Leo van den Berg 2000, Toward a Sustainable Relationship between City and University, A Stakeholdership Approach, Journal of Planning Education and Research, DOI: 10.1177

Brook McIlroy, 2008, York University Background Study Land Use, Urban Design and Heritage, City of Toronto City Planning Division York University Development Corporation

Busha, C. H., \& Harter, S. P. (1980). Research methods in librarianship: Academic press. 